\title{
Shear stress promotes differentiation of stem cells from human exfoliated deciduous teeth into endothelial cells via the downstream pathway of VEGF-Notch signaling
}

\author{
PENGLAI WANG $^{1 *}$, SHAOYUE ZHU ${ }^{2 *}$, CHANGYONG YUAN $^{1}$, \\ LEI WANG ${ }^{3}$, JIANGUANG XU ${ }^{4}$ and ZONGXIANG LIU ${ }^{5}$ \\ ${ }^{1}$ Dental Implant Center and Departments of ${ }^{2}$ Orthodontics and ${ }^{3}$ Periodontics, \\ Xuzhou Stomatological Hospital, Xuzhou, Jiangsu; ${ }^{4}$ The Discipline of Endodontology, \\ Faculty of Dentistry, The University of Hong Kong, Hong Kong, SAR; \\ ${ }^{5}$ Department of ExperDignosis, Xuzhou Stomatological Hospital, Xuzhou, Jiangsu, P.R. China
}

Received October 10, 2017; Accepted June 21, 2018

DOI: $10.3892 / \mathrm{ijmm} .2018 .3761$

\begin{abstract}
Effects of shear stress on endotheliaxl differentiation of stem cells from human exfoliated deciduous teeth (SHEDs) were investigated. SHEDs were treated with shear stress, then reverse transcription-quantitative polymerase chain reaction (RT-qPCR) was performed to analyse the mRNA expression of arterial markers and western blot analysis was performed to analyse protein expression of angiogenic markers. Additionally, in vitro matrigel angiogenesis assay was performed to evaluate vascular-like structure formation. The secreted protein expression levels of the vascular endothelial growth factor (VEGF) of SHEDs after shear stress was also quantified using corresponding ELISA kits. Untreated SHEDs seeded on Matrigel cannot form vessel-like structures at any time points, whereas groups treated with shear stress formed a few vessel-like structures at 4,8 and $12 \mathrm{~h}$. When SHEDs were treated with EphrinB2-siRNA for 24, the capability of vessel-like structure formation was suppressed. After being treated with shear stress, the expression of VEGF, VEGFR2, DLL4, Notch1, EphrinB2, Hey1 and Hey2 (arterial markers) gene expression was significantly upregulated, moreover, the protein levels of VEGFR2, EphrinB2, CD31, Notch1, DLL4, Hey1, and Hey2 were also significantly upregulated. Both the mRNA and protein expression levels of EphB4 (venous marker) were downregulated. The average VEGF protein concentration in supernatants secreted by shear stress treated
\end{abstract}

Correspondence to: Dr Zongxiang Liu, Department of ExperDignosis, Xuzhou Stomatological Hospital, 130 Huaihaixi Road, Xuzhou, Jiangsu 221000, P.R. China

E-mail: xzkqyylzx@163.com

*Contributed equally

Key words: angiogenesis, shear stress, SHEDs, EphrinB2, VEGF-DLL4/Notch signaling
SHEDs groups increased significantly. In conclusion, shear stress was able to induce arterial endothelial differentiation of stem cells from human exfoliated deciduous teeth, and VEGF-DLL4/Notch-EphrinB2 signaling was involved in this process.

\section{Introduction}

Post-natal mesenchymal stem cells derived from dental tissues, such as dental pulp stem cells (DPSCs), stem cells from human exfoliated deciduous teeth (SHEDs) and stem cells from apical papilla (SCAP) exhibit great multi-plasticity to differentiate into mesodermal lineages (1-3). Capability of differentiation into osteo/odontogenic, adipogenic and neurogenic lineages are inclusively used to confirm the stemness of mesenchymal stem cells. Notably, DPSCs and SHEDs have been successfully induced into endothelial cells in vitro and in vivo (4-7), along with bone marrow mesenchymal stem cells (BMMSCs) and human adipose-derived stem cells (ASCs) $(8,9)$.

It is well-known that vascular endothelial growth factor (VEGF), an endothelial cell mitogen is the best-defined regulator for inducing endothelial lineage differentiation from mesenchymal stem cells. Indeed, VEGF-A combined with its cognate VEGF receptor 2, effectively increases BMMSCs, ASCs, DPSCs and SHEDs differentiation into endothelial cells $(4,5,8$, and 9). The VEGF-Notch-EphrinB2 pathway was reported to regulate arterial-venous specification (10). During vessel sprouting, activation of VEGFR2 by VEGF induces tip cell migration and upregulates Notch ligand Delta-like 4 (DLL4) expression, which in turn interacts Notch receptors on neighboring endothelial cells (ECs), subsequently upregulates VEGFR1, metabolizing VEGF (11).

Substrate elasticity and biomechanical force are important factors of stem cell niche. Mechanical cues could modulate stem cell differentiation, division, survival, and motility (12). Studies have shown that shear stress can activate Notch signaling, triggering endothelial differentiation into the arterial phenotype (13). For example, shear stress induced arterial specification of embryonic stem (ES)-derived ECs 
and endothelial progenitor cells $(14,15)$. Shear stress or combination with VEGF induced BMMSC differentiation into endothelial cells (16).

To the best of our knowledge, there are no reports on shear stress on the endothelial differentiation of SHEDs. In this study, we investigated: i) The cell stemness of SHEDs, ii) the impact of shear stress on the endothelial differentiation, and iii) the molecular mechanism by which shear stress induces endothelial differentiation.

\section{Materials and methods}

Culture and characterization of SHEDs. The 3rd passage SHEDs were a gift from Dr Jianguang Xu (The University of Hong Kong, Hong Kong, SAR, China). Cells were cultured in $\alpha$-MEM supplemented with $10 \%(\mathrm{v} / \mathrm{v}) \mathrm{FBS}$ and $1 \%(\mathrm{v} / \mathrm{v})$ penicillin/streptomycin at $37^{\circ} \mathrm{C}$ in a $5 \% \mathrm{CO}_{2}$ humidified incubator to $70 \%$ confluence, 4 th to 6 th passage cells were used in later experiments. Cell 'stemness' of SHEDs were evaluated before induction. The expression of cell surface markers, CD90, CD73, CD45, STRO-1, and CD105 was assessed by flow cytometry (BD Biosciences, Franklin Lakes, CA, USA). Additionally, osteo/odontogenic, adipogenic, and neurogenic differentiation assays were conducted in the respective induction media.

Shear stress experiments. Glass slides (Flexcell International, Hillsborough, NC, USA) were coated with Cultrex ${ }^{\circledR}$ Rat Collagen I (R\&D Systems, Inc., Minneapolis, MN, USA) at a concentration of $5 \mu \mathrm{g} / \mathrm{cm}^{2}$ and incubated at $37^{\circ} \mathrm{C}$ for $1 \mathrm{~h}$ before usage. SHEDs grown to $70 \%$ confluence were trypsinized and counted. Before shear stress treatment, SHEDs $\left(3 \times 10^{5}\right.$ cells $\left./ \mathrm{ml}\right)$ were seeded in glass slides (Flexcell International) for $4 \mathrm{~h}$, followed by transfer to 4-well sterile dishes (Thermo Fisher Scientific, Inc., Waltham, MA, USA) with $4 \mathrm{ml} \alpha$-MEM supplemented with $15 \%(\mathrm{v} / \mathrm{v})$ FBS to achieve $80-90 \%$ confluence. Then, the glass slides were transferred to Streamer ${ }^{\circledR}$ Shear Stress Device (Flexcell International). After shear stress values of 4 and 16 dynes $/ \mathrm{cm}^{2}$ for $2 \mathrm{~h}$, supernatants were collected for later ELISA assay and cells were harvested for reverse transcription-quantitative polymerase chain reaction (RT-qPCR) and protein analyses. Cells without treatment were used as control groups.

Combine shear stress with VEGF. SHEDs on glass slides after shear stress treatment were transferred to 4-well sterile dishes (Thermo Fisher Scientific, Inc.), 4 ml FBS-free $\alpha$-MEM supplemented with VEGF (50 ng/ml) (R\&D Systems, Inc.) was added to each well. Cells were cultured for $12 \mathrm{~h}$ before being harvested for RT-qPCR and western blot analysis. Cells without VEGF treatment were used as control groups.

In vitro Matrigel angiogenesis assay. To assess whether shear stress induced SHEDs could promote angiogenesis, the in vitro Matrigel angiogenesis assay was conducted as described previously (17). Briefly, different groups of cells (4 dynes $/ \mathrm{cm}^{2}$ shear stress induced SHEDs, 16 dynes $/ \mathrm{cm}^{2}$ shear stress induced SHEDs and primary SHEDs groups) were seeded at 70,000 cells per well of labeled and $120 \mu \mathrm{l}$ liquid Matrigel (cat. no. 354230; BD Biosciences, Franklin Lakes, NJ,
Table I. Primer sequences.

\begin{tabular}{ll}
\hline Genes & \multicolumn{1}{c}{ Primers } \\
\hline VEGF & F: TTCATGGATGTCTATCAGCG \\
& R: CATCTCTCCTATGTGCTGGC \\
VEGFR2 & F: TCAGAAGAACTGAAAACTTTGGAA \\
& R: GAGCCTTCAGATGCCACACACT \\
DLL4 & F: TGCAACTGCCCTTATGGCTTTGTG \\
& R: ACAAGTTGTCATGGCTTCCCTGC \\
Notch1 & F: TCCACCAGTTTGAATGGTCA \\
& R: AGCTCATCATCTGGGACAGG \\
EphrinB2 & F: TGGATCACCTGAAAATGCTG \\
Rey1 & R: CGAAATCCCAAACTCCGATA \\
& F: TGGATCACCTGAAAATGCTG \\
Rey2 & R: CGAAATCCCAAACTCCGATA \\
& F: GTGCGGCTTGTGTCTCATCTC \\
EphB4 & R: CTGCTGCTGCTGCGTTTG \\
& F: AGAGGCCGTACTGGGACATGAG \\
CD31 & R: TCCAGCATGAGCTGGTGGAG \\
& F: CCCAGCCCAGGATTTCTTAT \\
& R: ACCGCAGGATCATTTGAGTT \\
& F: GGCATGGACTGTGGTCATGAG \\
& R: TGCACCACCAACTGCTTAGC
\end{tabular}

F, forward; R, reverse.

USA) pre-coated 48-well plates. After being incubated for 2, 4, 6 and $8 \mathrm{~h}$ at $37^{\circ} \mathrm{C}$ and $5 \% \mathrm{CO}_{2}$. Images were captured using an inverted microscope (Olympus, Tokyo, Japan). In addition, to investigate whether VEGF-DLL4/Notch-EphrinB2 signaling pathway is involved, SHEDs were transfected with EphrinB2 small interfering RNA (EphrinB2-siRNA) (Thermo Fisher Scientific, Inc.). Briefly, SHEDs were seeded on 24-well plates to $80 \%$ confluence, RNA-lipid complexes was prepared by mixing $50 \mu \mathrm{l}$ Opti-MEM Medium (Thermo Fisher Scientific, Inc.) and $3 \mathrm{ml}$ Lipofectamine and RNAiMAX reagent (Invitrogen; Thermo Fisher Scientific, Inc.) together. siRNA $1 \mu \mathrm{l}(10 \mathrm{pmol})$ was diluted in $50 \mu \mathrm{l}$ Opti-MEM Medium before being mixed with diluted Lipofectamine and RNAiMAX reagent at a ratio of 1:1. Then the siRNA-lipid complex was incubated for $5 \mathrm{~min}$ at room temperature. SHEDs were incubated with the siRNA-lipid complex for $24 \mathrm{~h}$ before the shear stress experiments and in vitro Matrigel angiogenesis assay were performed. Quantification of vessel-like structures performed using the Nikon NIS-Elements AR 3.1 imaging software (Kawasaki, Kanagawa, Japan). The tubule length and branching points were measured on $\mathrm{x} 4$ magnification images $(n=3)$.

$R T-q P C R$. Total RNA of different time points were extracted with the RNeasy Plus mini kit (Qiagen $\mathrm{GmbH}$, Hilden, Germany) (18). Sample of total RNA $(1.0 \mu \mathrm{g})$ was used to synthesize complementary DNA by cDNA Synthesis (SuperScript $^{\mathrm{TM}}$ III Reverse Transcriptase, Invitrogen; Thermo 
A
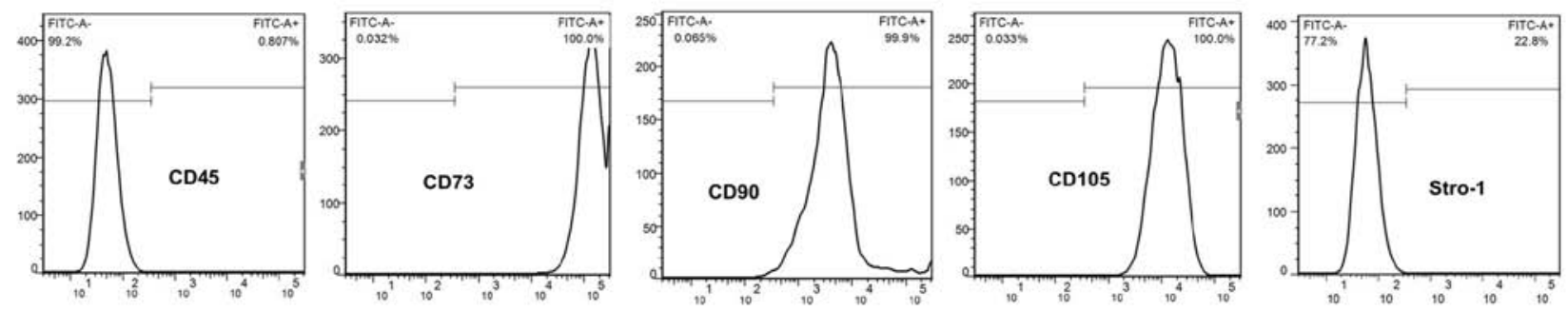

B

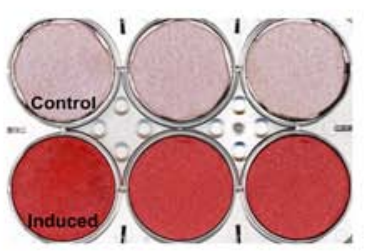

C

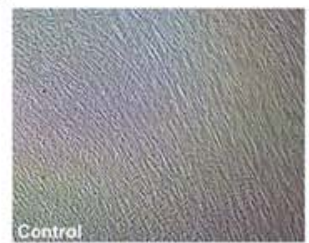

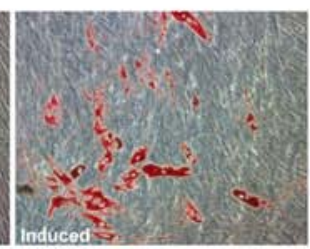

D

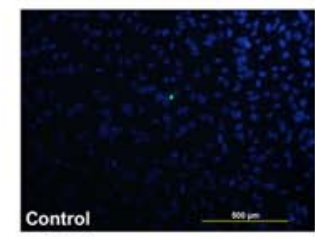

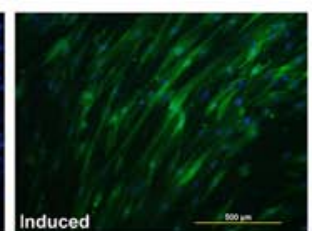

Figure 1. Characterization of stem cells from human exfoliated deciduous teeth (SHEDs). (A) Flow cytometry results of stem cell markers CD45, CD90, CD105, CD73, and STRO-1. (B) Alizarin Red staining of mineralization after 4 weeks of induction. (C) Oil Red O detection of lipid droplets after 4 weeks of induction (x10). (D) Immunofluorescence imaging of $\beta$ III-tubulin after 4 weeks of induction (scale line $500 \mu \mathrm{m}$ ).

A

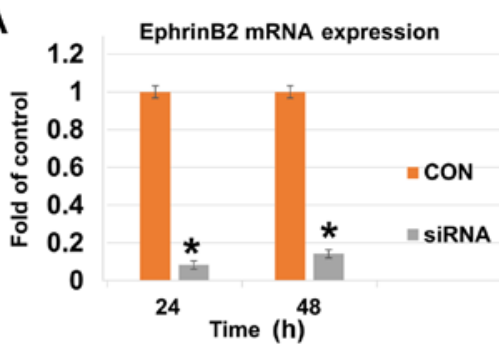

\section{B}
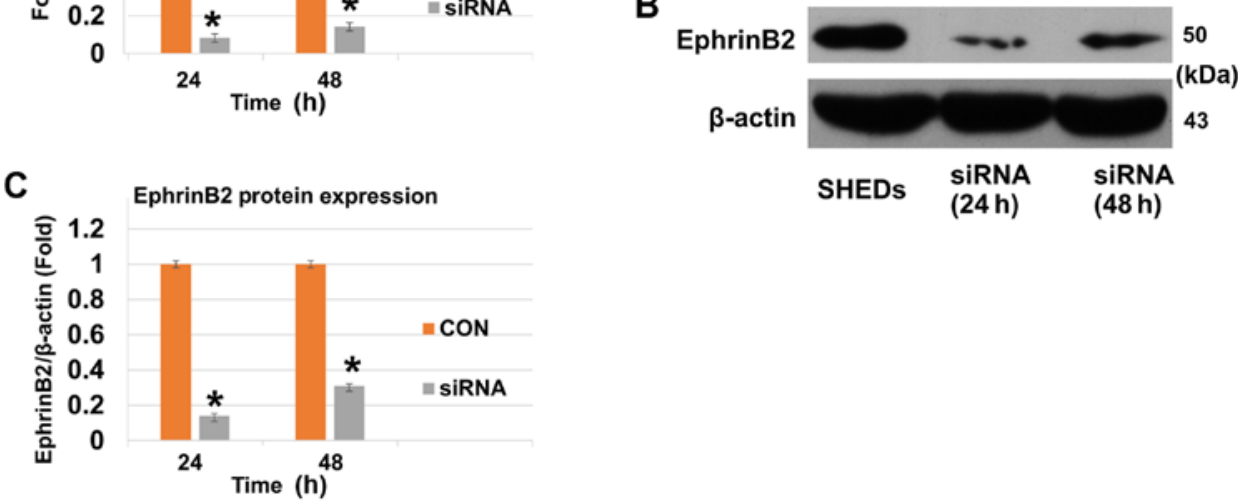

Figure 2. EphrinB2 expression after transfection with EphrinB2-siRNA. (A) The mRNA expression of EphrinB2 after transfected with EphrinB2-siRNA. $(B$ and $C)$ The protein expression of EphrinB2 in SHEDs after transfected with EphrinB2-siRNA. ("P<0.05).

Fisher Scientific, Inc.) RT-qPCR was performed with the ABI Prism 7000 Sequence Detection System using fast-SYBR Green (Applied Biosystems; Thermo Fisher Scientific, Inc.), Standards and samples were run in triplicates. Primer sequences were shown in Table I.

Western blot analysis. Cells grown in glass slides were treated with shear stress for $2 \mathrm{~h}$. Then total protein was obtained by using M-PER protein extraction buffer, and quantified using a BCA kit (Thermo Fisher Scientific, Inc.) and separated on 7.5 or $12 \%$ polyacrylamide gel followed by transfer onto an ImmunBlot PVDF membrane (GE Healthcare Life Sciences, Little Chalfont, UK). The membranes were blocked for $1 \mathrm{~h}$ with 5\% BSA in Tris-phosphate buffer containing 0.05\% Tween-20 (TBS-T). It was further incubated overnight at $4^{\circ} \mathrm{C}$ with antiNotch1 (1:2,000; ab52627), anti-DLL4 (1:1,000; ab7280),
anti-Heyl (2 $\mu \mathrm{g} / \mathrm{ml}$, ab22614), anti-Hey2 (2 $\mu \mathrm{g} / \mathrm{ml}$; ab25404) all from Abcam (MA, USA); anti-EphrinB2 (1:1,000; sc-398735) and anti-EphB4 (1:1,000; sc-130081) both from Santa Cruz Biotechnology, Inc. (Dallas, TX, USA); anti-VEGFR2 (1:2,000; ab39256) and anti-CD31 (1:500; ab28364) both from Abcam, primary antibodies. After three washes (5 min) with TBS-T, membranes were further incubated with HRP-conjugated secondary antibodies: anti-rabbit (cat. no. 7074) or anti-mouse (cat. no. 7076) both from Cell Signaling Technology, Inc., (Danvers, MA, USA) for 1-2 $\mathrm{h}$ and followed by three washes with TBS-T. The target protein signal was detected and digitized using ECL (Thermo Fisher Scientific, Inc.).

ELISA. The above collected supernatants were used for VEGF secreted protein detection. The secreted levels of VEGF were quantified using corresponding Human VEGF ELISA 
A

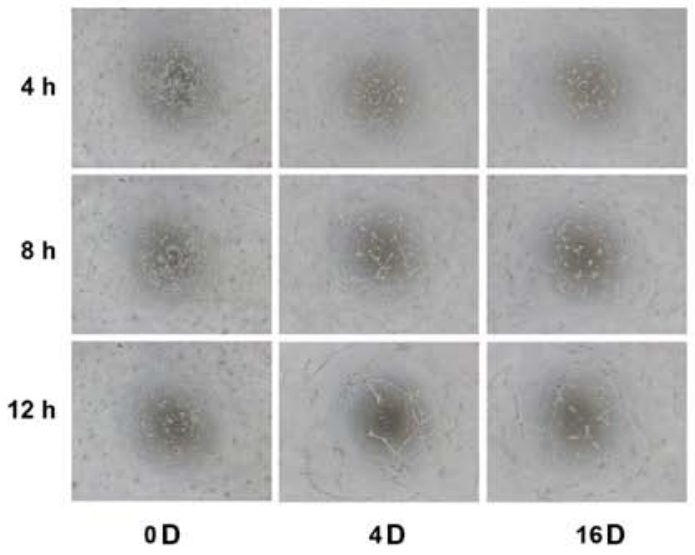

B

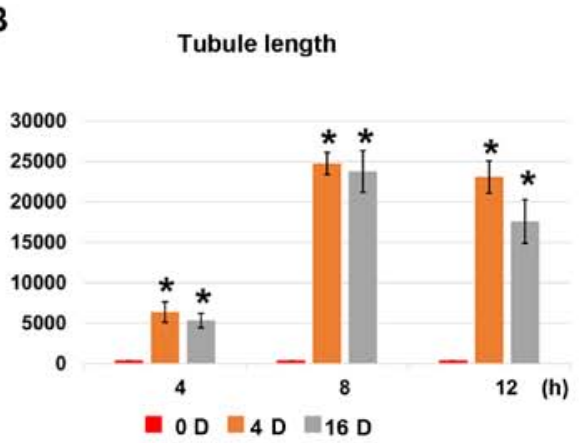

C Branching points number

D

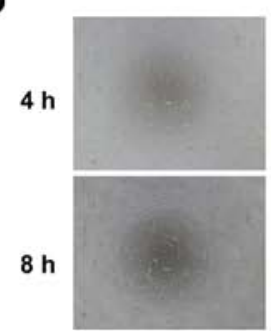

OD

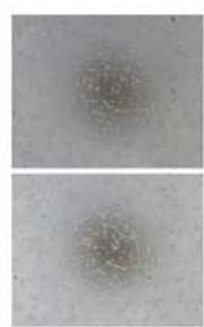

4D

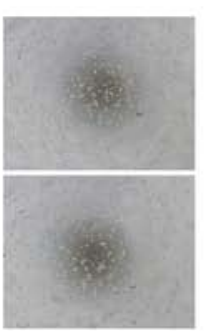

16D
E

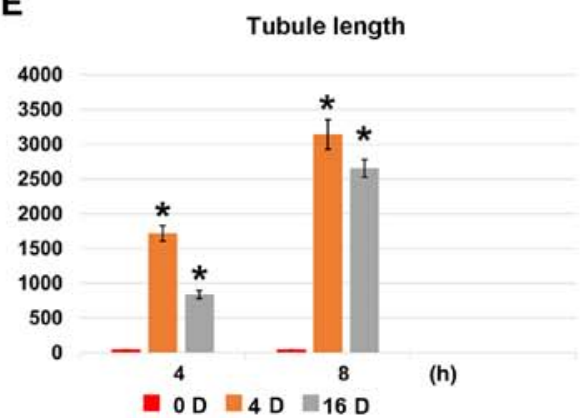

$\mathbf{F}$

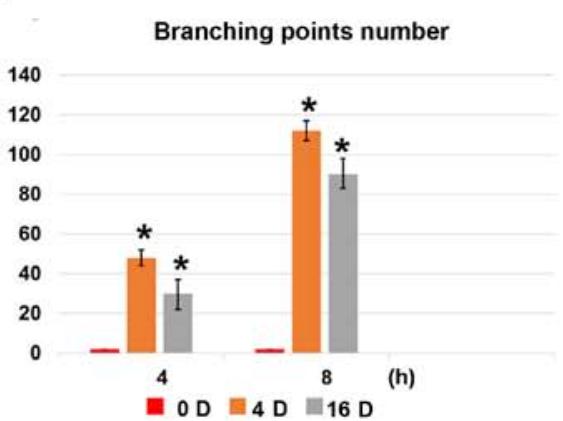

Figure 3. The formation of vessel-like structures of SHEDs. (A) SHEDs subjected to shear stress $\left(4 \mathrm{and} 16 \mathrm{dynes} / \mathrm{cm}^{2}, 2 \mathrm{~h}\right)$ treatment were reseeded onto matrigel for in vitro angiogenesis assay. Vessel-like structures of SHEDs at 4, 8 and $12 \mathrm{~h}$ were detected using an inverted microscope (x4). (B) Comparison of tubule length between different shear stress value groups. (C) Comparison of branching points between different shear stress value groups. (D) SHEDsEphrinB2-RNAi subjected to shear stress (4 and 16 dynes $/ \mathrm{cm}^{2}, 2 \mathrm{~h}$ ) treatment were reseeded onto matrigel for in vitro angiogenesis assay. Vessel-like structures of SHEDs at 4 , and $8 \mathrm{~h}$ were detected using an inverted microscope (x4). (E) Comparison of tubule length between different shear stress value groups. (F) Comparison of branching points between different shear stress value groups $\left({ }^{*} \mathrm{P}<0.05\right)$.

kits (DY293B; R\&D Systems, Inc.). Briefly, supernatants were centrifuged at $3,500 \mathrm{x}$ g for $5 \mathrm{~min}$, at $4^{\circ} \mathrm{C}$ to remove any impurity. Microplate strips were removed from the plate frame. Assay Diluent RD1W (50 $\mu$ l) (R\&D Systems, Inc.) was 
A

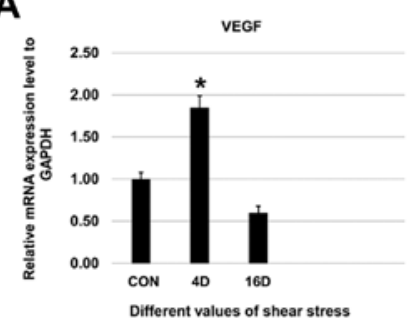

D

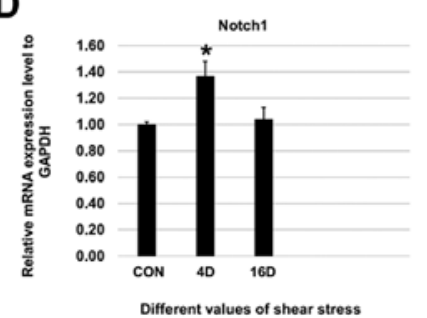

G

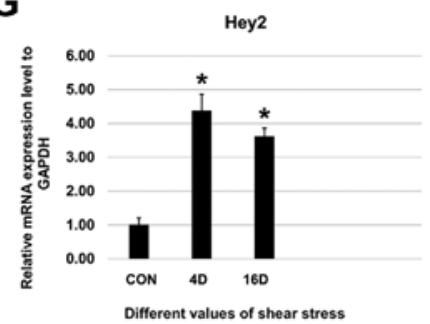

B

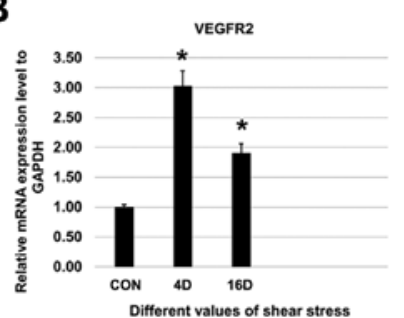

E

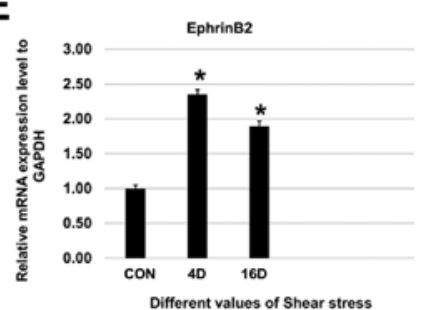

H

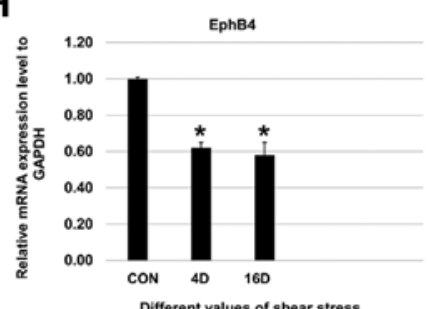

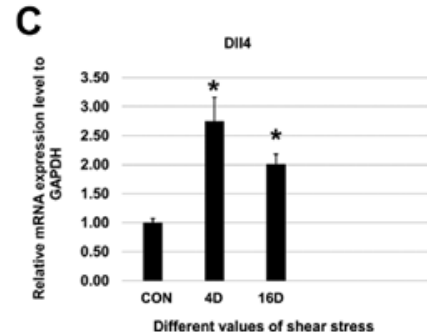

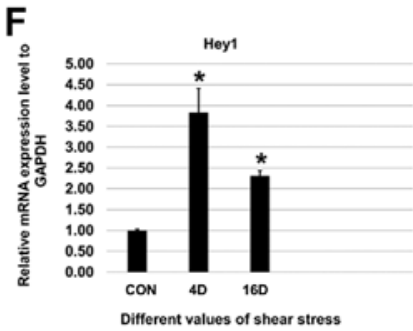

Figure 4. (A-H) Relative mRNA expression levels of VEGF, VEGFR2, DLL4, Notch1, EphrinB2, Hey1, Hey2 and EphB4 of SHEDs after shear stress (4 and 16 dynes $\left./ \mathrm{cm}^{2}\right)$ for $2 \mathrm{~h}$. Values were normalized to GAPDH expression $\left({ }^{*} \mathrm{P}<0.05\right)$.

added to each well. Then, $200 \mu \mathrm{l}$ of VEGF standards, controls, or samples were added to each well. Wells were covered with a plate sealer and incubated at room temperature for $2 \mathrm{~h}$. After 3 washes, $200 \mu \mathrm{l}$ VEGF conjugate was added and incubated at room temperature for $20 \mathrm{~min}$ in the dark followed by adding $50 \mu \mathrm{l}$ of Stop Solution (R\&D Systems, Inc.) to each well. Light absorption values were read within 30 min using a microplate reader (Molecular Devices, San Jose, USA) (450 nm).

Statistical analysis. All experiments were performed in triplicates and repeated at least 3 times. Data are expressed as mean \pm standard deviation (SD). One way ANOVA analysis of variance with Tukey's post hoc test was utilized in multiple comparisons between the groups. P-value $<0.05$ was considered to be statistically significant.

\section{Results}

SHEDs show stem cell characteristics. SHEDs displayed a fibroblastic spindle or stellate shape in $\alpha$-MEM. Flow cytometric analyses revealed high expression levels of CD90, CD73, and CD105, but low expression levels of CD45; $22.8 \%$ of the SHED population expressed STRO-1 (Fig. 1A). Mineralization (Fig. 1B), lipid droplets (Fig. 1C) and neurogenic marker $\beta$ III-tubulin expression (Fig. 1D) were verified after induction in osteogenic, adipogenic and neurogenic media, respectively.
EphrinB2-siRNA suppresses $m R N A$ and protein expression of EphrinB2. To determine the EphrinB2 expression levels of SHEDs after being incubated with EphrinB2-siRNA, RT-qPCR and western blot analysis were performed. When SHEDs were incubated with EphrinB2-siRNA for 24 and $48 \mathrm{~h}$, both mRNA and protein expression of EphrinB2 was significantly decreased (Fig. 2A-C).

Shear stress enhances the formation of vessel-like structures of SHEDs. Untreated SHEDs seeded on Matrigel cannot form vessel-like structures at any time points (Fig. 3A). Groups treated with shear stress (4 and 16 dynes $/ \mathrm{cm}^{2}$ ) formed a small number of vessel-like structures at $4 \mathrm{~h}$ (Fig. 3A). The average total tubule length was more than 5,000 $\mu \mathrm{m}$ (Fig. 3B), and the number of branching points was more than 200 (Fig. 3C). The average total tubule reached about $25,000 \mu \mathrm{m}$ at $8 \mathrm{~h}$ in both treated groups and began to degrade afterwards. When SHEDs were treated with EphrinB2 siRNA (SHEDs-EphrinB2-RNAi), the vessel-like structure formation capacity was restrained (Fig. 3D), with an average total tubule length less than $3,500 \mu \mathrm{m}$ in each group and the number of branching points less than 120 at $8 \mathrm{~h}$ (Fig. 3E and F).

Effect of shear stress on the mRNA expression levels of VEGF, VEGFR2, DLL4, Notch1, Hey1, Hey2, EphrinB2, EphB4 and CD31. Shear stress (4 and 16 dynes $/ \mathrm{cm}^{2}$ ) upregulated the mRNA expression levels of endothelial cell markers (VEGF, 
A
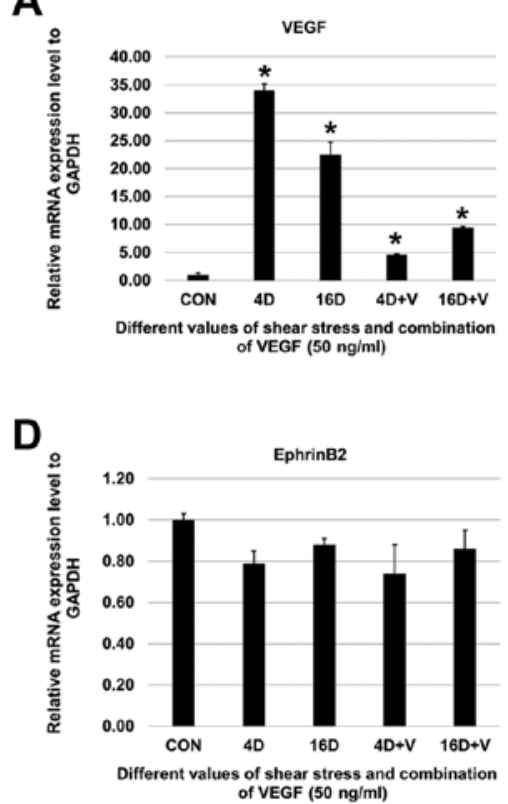

B

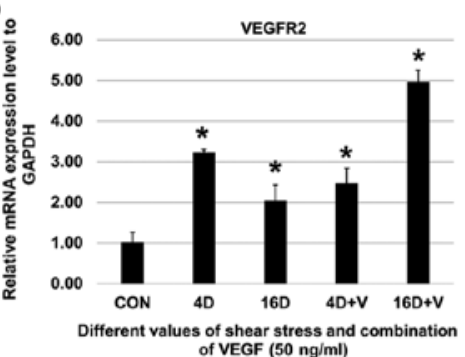

E

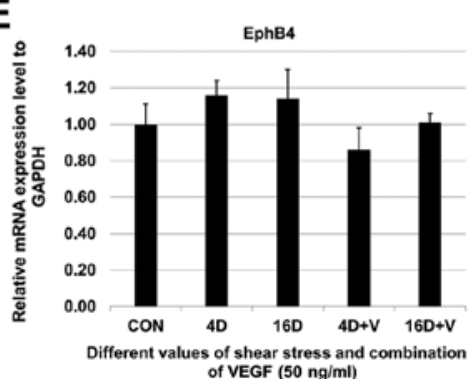

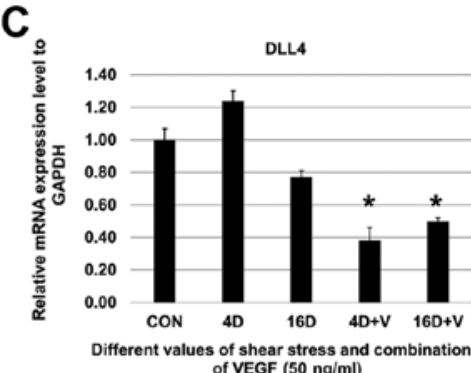

of VEGF ( $50 \mathrm{ng} / \mathrm{ml})$

$\mathbf{F}$

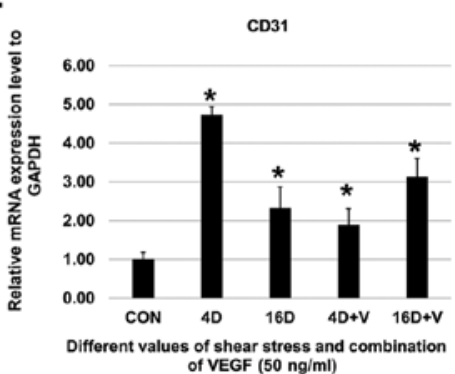

Figure 5. (A-F) Relative mRNA expression levels of VEGE, VEGFR2, DLL4, EphrinB2, EphB4 and CD31 of SHEDs after shear stress (4 and 16 dynes/cm²) treatment for $2 \mathrm{~h}$ and VEGF induction for $12 \mathrm{~h}$. Values were normalized to GAPDH expression ( $\mathrm{P}<0.05)$.

A

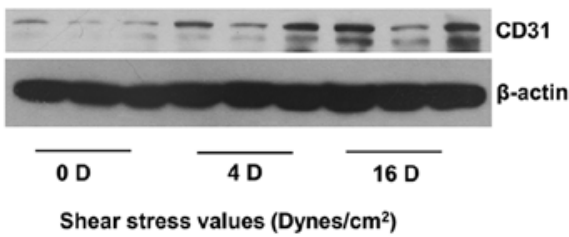

B

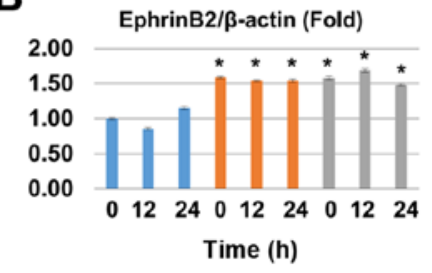

D

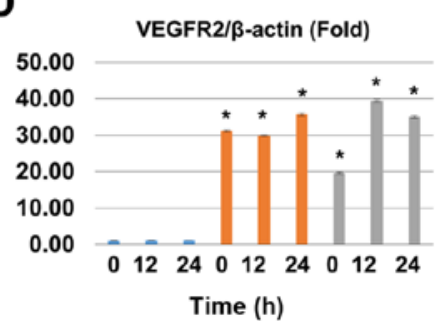

C

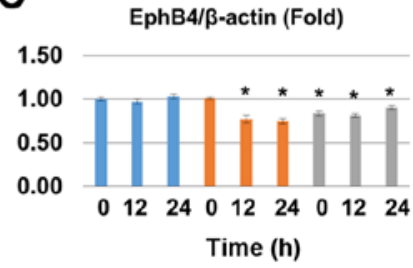

E

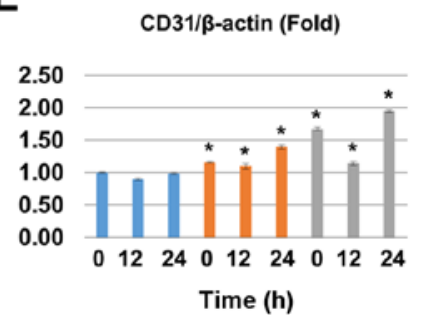

Figure 6. Protein expression of EphrinB2, EphB4, VEGFR2, and CD31 in SHEDs after shear stress treatment. Three different protein extraction time points $(0,12$, and 24 h) were chosen. (A) EphrinB2, EphB4, VEGFR2 and CD31 protein expression. (B) Quantification bands of EphrinB2. (C) EphB4. (D) VEGFR2 and (E) CD31. ( $\left.{ }^{*} \mathrm{P}<0.05\right)$.

VEGFR2, and DLL4) (Fig. 4A-C) and arterial endothelial cell specific markers (Notch1, EphrinB2, Hey1 and Hey2) (Fig. 4D-G). However, the venous endothelial cell specific marker expression (EphB4) was downregulated (Fig. 4H). Of note, compared to control groups, mRNA expression levels of VEGF and Notch-1 increased significantly when SHEDs were exposed to 4 dynes $/ \mathrm{cm}^{2}$ groups while there was no significant difference in 16 dynes $/ \mathrm{cm}^{2}$ groups (Fig. 4A and D). After shear stress treatments, SHEDs were cultured in FBS-free $\alpha$-MEM supplemented with VEGF $(50 \mathrm{ng} / \mathrm{ml})$ for $12 \mathrm{~h}$. The mRNA expression levels of VEGF, VEGFR2, and CD31 were upregulated significantly (Fig. 5A, B and F) while there were no significant changes in mRNA expression levels of EphrinB2 and EphB4 (Fig. 5D and E). Noteworthy, mRNA expression levels of DLL4 decreased significantly when VEGF was added (Fig. 5C).

Effect of shear stress on the protein expression levels of EphrinB2, VEGFR2, EphB4, and CD31 in SHEDs. After shear stress $\left(4\right.$ and 16 dynes $\left./ \mathrm{cm}^{2}\right)$ treatment for $2 \mathrm{~h}$, we chose three different protein extraction time points $(0,12$, and $24 \mathrm{~h})$ to perform western blot assay. The protein expression level of EphrinB2 was upregulated significantly in shear stress groups (Fig. 6A and B). The protein level of VEGFR2 cannot be detected in non-induced groups but was significantly upregulated in shear stress treatment groups while the protein level 
A

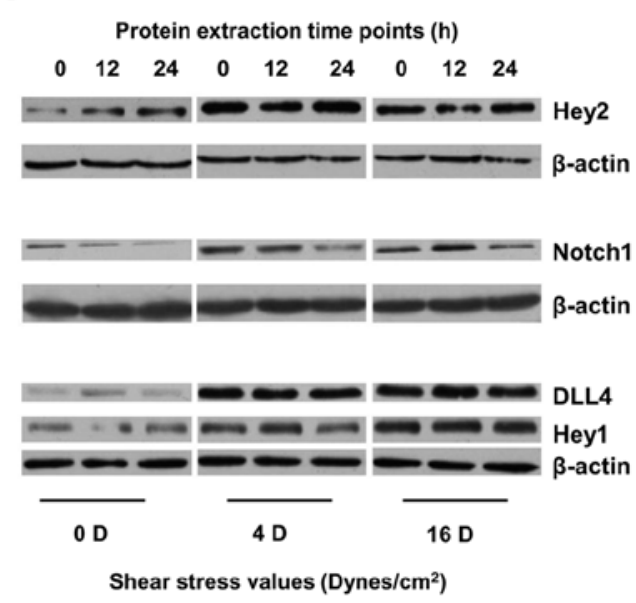

B

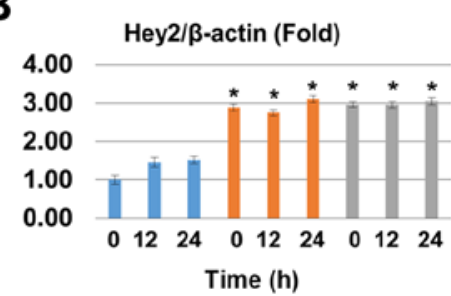

D

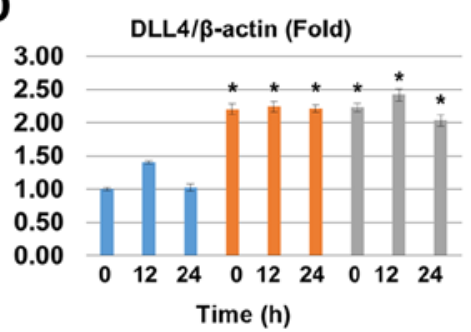

C

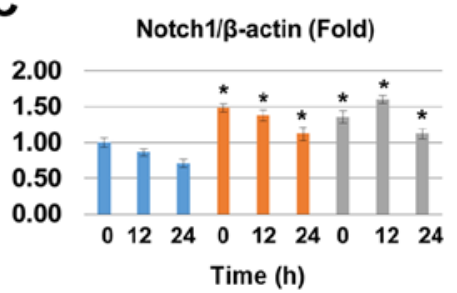

E

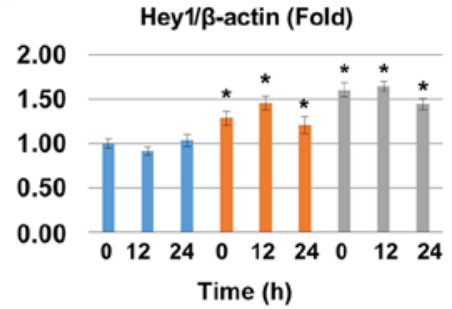

Figure 7. Protein expression of Hey2, Notch1, DLL4, and Hey1 in SHEDs after shear stress treatment. Three different protein extraction time points $(0,12$, and 24 h) were chosen. (A) Hey2, Notch1, DLL4 and Hey1 protein expression. (B) Quantification bands of Hey2. (C) Notch1. (D) DLL4 and (E) Hey1. ("P<0.05).

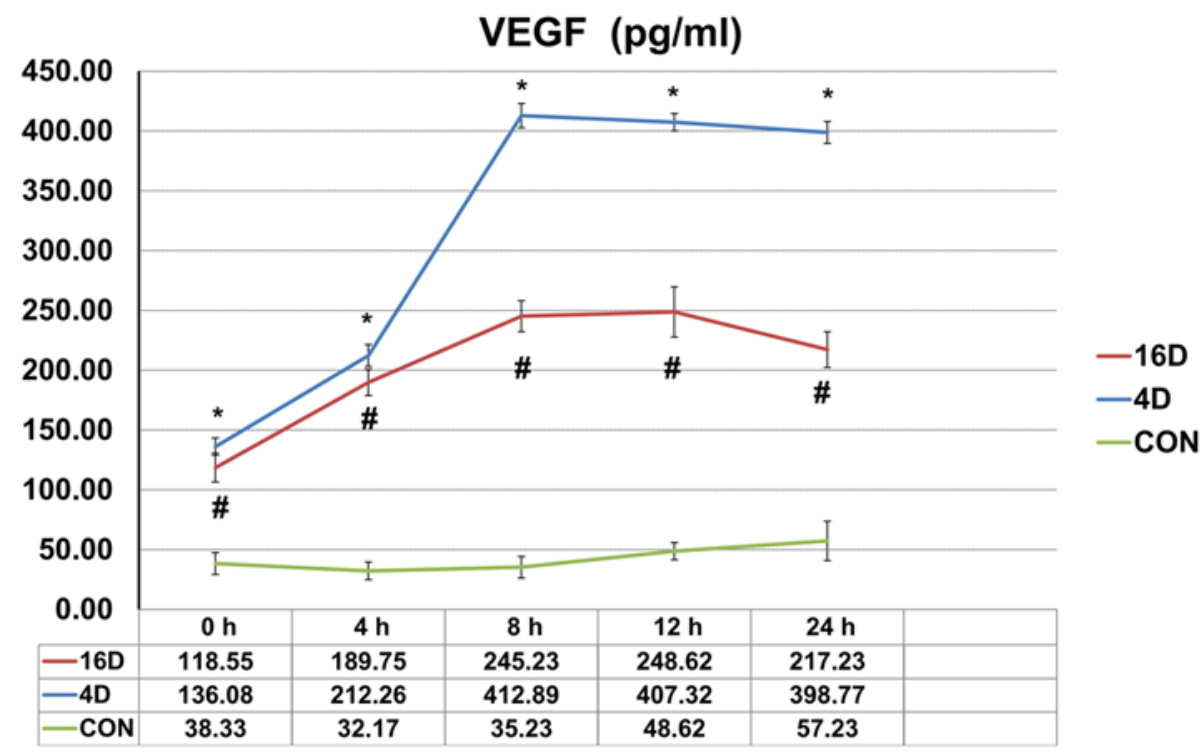

Figure 8. The secreted levels of VEGF at $0,4,8,12,24 \mathrm{~h}$ collecting time points after shear stress was detected. To detect the secreted protein expression levels of VEGF, enzyme-linked immunosorbent assay (ELISA) was performed. $\left({ }^{*}, \mathrm{P}<0.05\right)$.

of EphB4 was downregulated in shear stress groups (Fig. 6A, $\mathrm{C}$, and D). The protein level of CD31 was significantly upregulated in shear stress treatment groups (Fig. 6A and E). The protein level of Hey2, Notch1, DLL4 and Hey1 were upregulated significantly in shear stress groups (Fig. 7A-E).

The secreted levels of VEGF in supernatants. To investigate the mechanisms by which shear stress in promoting the endothelial differentiation of SHEDs, ELISA assay was performed using the Human VEGF Quantikine ELISA kit. The ELISA results showed that the average VEGF protein concentration in supernatants secreted by untreated SHEDs groups was no more than $60 \mathrm{pg} / \mathrm{ml}$. When SHEDs were treated with 4 dynes $/ \mathrm{cm}^{2}$ (16 dynes $/ \mathrm{cm}^{2}$ ) shear stress, the secreted levels of VEGF increased to $136.08 \mathrm{pg} / \mathrm{ml}(118.55 \mathrm{pg} / \mathrm{ml}), 212.26 \mathrm{pg} / \mathrm{ml}$ (189.75 pg/ml), $412.89 \mathrm{pg} / \mathrm{ml}$ (245.23 pg/ml), $407.32 \mathrm{pg} / \mathrm{ml}$
(248.62 pg/ml), $398.77 \mathrm{pg} / \mathrm{ml}(217.23 \mathrm{pg} / \mathrm{ml})$ at $0,4,8,12$ and $24 \mathrm{~h}$ time points (Fig. 8).

\section{Discussion}

Previous studies suggested that shear stress could induce arterial specification of endothelial cells derived from human induced pluripotent stem cells (hiPSC-ECs) and SHH-VEGFNotch-DLL4-EphrinB2 signaling is involved in this process $(10,13,14,19)$. However, some other studies also argued that shear stress failed to induce endothelial differentiation of human adipose tissue mesenchymal stem cells (hASC) (20). Besides, previous research demonstrated that two-dimension (2D) and three-dimension (3D) environments had a different effect on cell differentiation, drug metabolism and gene and protein expression levels. 3D chitos and conduit together with 
dynamic culture system promoted the cells aggregated into neurosphere-like cells while this effect was not found in 2D culture environment $(21,22,23)$. Our previous studies revealed that TGF- $\beta 1$ induced differentiation of SHEDs into vascular smooth muscle cells (vSMCs) (24). Also, the decellularized extracellular matrix of human umbilical vein endothelial cells (HUVECs) promoted endothelial differentiation of SHEDs (25). However, the effect of biomechanical force on the differentiation of SHEDs was yet to be demonstrated.

In the present study, we found SHEDs possess unique stem cell characteristics, as high as $22.8 \%$ of the SHED population expressed STRO-1, which is the widely-known mesenchymal stem cell (MSC) marker (26). Besides, mineralization, lipid droplets, and neurogenic marker $\beta$ III-tubulin expression were verified after induction in osteogenic, adipogenic and neurogenic media, respectively. These findings suggested SHEDs might be a favorable candidate for our study.

To investigate the impact of shear stress on the endothelial differentiation of SHEDs, in vitro matrigel angiogenesis assay was performed as previously described (17). Untreated groups, shear stress $\left(2 \mathrm{~h}, 4\right.$ dynes $\left./ \mathrm{cm}^{2}\right)$ treated groups and shear stress $\left(2 \mathrm{~h}, 16\right.$ dynes $\left./ \mathrm{cm}^{2}\right)$ treated groups were seeded on Matrigel, respectively, tubule length at 4, 8 and $12 \mathrm{~h}$ was quantified. Untreated SHEDs seeded on Matrigel cannot form vessel-like structures at any time points, whereas groups treated with shear stress $\left(4\right.$ dynes $\left./ \mathrm{cm}^{2}\right)$ formed a small number of vessel-like structures at $4 \mathrm{~h}$. When SHEDs were treated with EphrinB2 siRNA, the vessel-like structure formation capacity was restrained, which indicated that EphrinB2 signaling pathway is involved in the endothelial differentiation process of SHEDs. Of note, compared with 4 dynes $/ \mathrm{cm}^{2}$ groups, groups treated with shear stress (16 dynes $/ \mathrm{cm}^{2}$ ) formed less vessel-like structures, which implied that shear stress values of 4 dynes $/ \mathrm{cm}^{2}$ performed more effectively in this process.

To further evaluate the endothelial differentiation of SHEDs, RT-qPCR and western blot analysis were performed. After shear stress induction for $2 \mathrm{~h}$, the mRNA expression of VEGF, VEGFR2, EphrinB2, DLL4, Notch1, Hey1 and Hey2 (arterial markers) in SHEDs increased significantly, whereas the expression of EphB4 (venous mark) decreased. The protein expression of Hey1, Hey2, Notch1, DLL4, EphrinB2, VEGFR2 and CD31 was upregulated significantly after shear stress treatment while the protein expression of EphB4 was downregulated, these findings were consistent with previous studies $(13,14)$. When the SHEDs were cultured in FBS-free aMEM combined with or without VEGF $(50 \mathrm{ng} / \mathrm{ml})$ for $12 \mathrm{~h}$ after shear stress, the mRNA expression of VEGF, VEGFR2, and CD31 was upregulated significantly, while the expression levels of EphrinB2 and EphB4 had no significant changes. We speculated that this might be related to the limited plasticity of post-natal mesenchymal stem cells (27). In addition, arterial marker EphrinB2 and venous marker EphB4 are known to act downstream of the SHH-VEGF-Notch-DLL4-EphrinB2 cascade in arterial-venous specification $(10,13,14,19,28)$. Shear stress for $2 \mathrm{~h}$ could not maintain the persistent high expression of mRNA of EphrinB2 and EphB4, even though VEGF $(50 \mathrm{ng} / \mathrm{ml})$ was added to the medium. Contrary to Shear stress per treatment, the mRNA expression levels of DLL4 was downregulated significantly when VEGF was added, suggesting that a negative-feedback loop between VEGF-DLL4/Notch signaling may exist as previously reported (29).

Based on these results, we assumed VEGF-DLL4/Notch1EphrinB2 cascade took place in this process as previously reported $(10,19)$. To prove our hypothesis, the secreted levels of VEGF at $0,4,8,12$, and $24 \mathrm{~h}$ in SHED culture supernatants after shear stress were quantified. Results showed that the concentration of VEGF in culture supernatants increased significantly after shear stress. VEGF is known as a strong stimulator of angiogenesis (30,31), it stimulates cellular responses by binding to tyrosine kinase receptors (the VEGFRs) on the cell surface. Among all the VEGFRs, VEGFR-2 (also known as KDR or Flk-1) mediate most of the known cellular responses when activated by VEGF (32). In this study, the protein level of VEGFR2 cannot be detected in non-induced groups but increased significantly in shear stress treatment groups, which implied the signaling pathway mediated by VEGF was activated $(30,32,33)$.

VEGF was reported as an upstream regulator of EphrinB2/EphB4 (34). Both EphrinB2 and EphB4 are expressed on endothelia and mural cells. EphrinB2 exists mainly on arterial endothelia and mural cells, while EphB4 prefers venous ECs. The EphrinB2/Eph4 receptor signaling pathway is known to play a key role in embryonic vascular development $(35,36)$, some regulatory genes including notch-1, VEGF, and DLL4 were reported to act as the upstream regulators of EphrinB2/EphB4 pathway activation (34). VEGF was reported to promote the protein expression of EphrinB2 in two ways: i) VEGF promotes expression of EphrinB2 directly, but can not promote EphrinB2 phosphorylation (37,38); and ii) VEGF activate DLL4/Notch pathway and selectively promote the expression of EphrinB2 (14), thus suggesting that there may exist a cascade among VEGF-DLL4/Notch-EphrinB2 in angiogenesis $(39,40)$. According to previous studies, VEGF was able to downregulate the expression levels of EphB4 in embryonic stem cells, HUVECs and adult ECs $(14,33)$, and the process was reported to be MAPK/ERK-dependent (33). Also, Notch signaling was also reported to inhibit EphB4 expression by overexpressing HERPs $(32,42)$. Besides, inhibition of EphB4 forward signaling was sufficient to inhibit VEGF-induced angiogenesis in vivo (43). Herein, the VEGF-DLL4/NotchEphrinB2 cascade may inhibit VEGF-induced angiogenesis through EphB4 forward signaling (44), suggesting that EphB4 forward signaling may involve in this negative feedback loop, but more studies have to be done to clarify the mechanisms.

In summary, our data confirmed that shear stress could induce arterial endothelial differentiation of SHEDs. Additionally, VEGF-DLL4/Notch1-EphrinB2 cascade took place in this process as previously demonstrated (10). This finding not only benefits the dental pulp tissue regeneration but also promotes the development of other subjects, such as the treatment of ischemic heart diseases.

\section{Acknowledgements}

Not applicable.

\section{Funding}

This work was supported by National Natural Science Foundation Youth Science Foundation project, no. 81700954. 


\section{Availability of data and materials}

The datasets generated or analyzed during the current study are available from the corresponding author on reasonable request.

\section{Authors' contributions}

PW, SZ and ZL designed the study and conducted the experiments. LW contributed to the acquisition and collection of the data. CY and JX were responsible for analyzing and interpreting the data. PW, CY, JX and SZ drafted the manuscript. All authors read and approved the final manuscript.

\section{Ethics approval and consent to participate}

Not applicable.

\section{Patient consent for publication}

Not applicable.

\section{Competing interests}

The authors declare that they have no competing interests.

\section{References}

1. Gronthos S, Mankani M, Brahim J, Robey PG and Shi S: Postnatal human dental pulp stem cells (DPSCs) in vitro and in vivo. Proc Natl Acad Sci USA 97: 13625-13630, 2000.

2. Miura M, Gronthos S, Zhao M, Lu B, Fisher LW, Robey PG and Shi S: SHED: Stem cells from human exfoliated deciduous teeth. Proc Natl Acad Sci USA 100: 5807-5812, 2003.

3. Huang GT-J, Sonoyama W, Liu Y, Liu H, Wang S and Shi S: The hidden treasure in apical papilla: The potential role in pulp/dentin regeneration and bioroot engineering. J Endod 34 645-651, 2008.

4. Zhang Z, Nor F, Oh M, Cucco C, Shi S and Nör JE: Wnt/ $\beta$-catenin signaling determines the vasculogenic fate of post-natal mesenchymal stem cells. Stem Cells 34: 1576-1587, 2016.

5. Bento LW, Zhang Z, Imai A, Nör F, Dong Z, Shi S, Araujo FB and Nör JE: Endothelial differentiation of SHED requires MEK1/ERK signaling. J Dent Res 92: 51-57, 2013.

6. Dissanayaka WL, Zhu L, Hargreaves KM, Jin L and Zhang C: Scaffold-free prevascularized microtissue spheroids for pulp regeneration. J Dent Res 93: 1296-1303, 2014.

7. Cordeiro MM, Dong Z, Kaneko T, Zhang Z, Miyazawa M, Shi S, Smith AJ and Nör JE: Dental pulp tissue engineering with stem cells from exfoliated deciduous teeth. J Endod 34: 962-969, 2008.

8. Zhang N, Chen B, Wang W, Chen C, Kang J, Deng SQ, Zhang B, Liu S and Han F: Isolation, characterization and multi-lineage differentiation of stem cells from human exfoliated deciduous teeth. Mol Med Rep 14: 95-102, 2016.

9. Qazi TH, Mooney DJ, Pumberger M, Geissler S and Duda GN: Biomaterials based strategies for skeletal muscle tissue engineering: Existing technologies and future trends. Biomaterials 53 . 502-521, 2015.

10. Lawson ND, Scheer N, Pham VN, Kim CH, Chitnis AB, CamposOrtega JA and Weinstein BM: Notch signaling is required for arterial-venous differentiation during embryonic vascular development. Development 128: 3675-3683, 2001.

11. Welti J, Loges S, Dimmeler S and Carmeliet P: Recent molecular discoveries in angiogenesis and antiangiogenic therapies in cancer. J Clin Invest 123: 3190-3200, 2013.

12. Lee H J,Li N, Evans SM, Diaz MF and Wenzel PL: Biomechanical force in blood development: extrinsic physical cues drive prohematopoietic signaling. Differentiation 86: 92-103, 2013.

13. Sivarapatna A, Ghaedi M, Le AV, Mendez JJ, Qyang Y and Niklason LE: Arterial specification of endothelial cells derived from human induced pluripotent stem cells in a biomimetic flow bioreactor. Biomaterials 53: 621-633, 2015.
14. Masumura T, Yamamoto K, Shimizu N, Obi S and Ando J: Shear stress increases expression of the arterial endothelial marker ephrinB2 in murine ES cells via the VEGF-Notch signaling pathways. Arterioscler Thromb Vasc Biol 29: 2125-2131, 2009.

15. Obi S, Yamamoto K, Shimizu N, Kumagaya S, Masumura T, Sokabe T, Asahara T and Ando J: Fluid shear stress induces arterial differentiation of endothelial progenitor cells. J Appl Physiol 1985 106: 203-211, 2009.

16. Bai K, Huang Y, Jia X, Fan Y and Wang W: Endothelium oriented differentiation of bone marrow mesenchymal stem cells under chemical and mechanical stimulations. J Biomech 43: 1176-1181, 2010.

17. Yuan C, Wang P, Zhu L, Dissanayaka WL, Green DW, Tong EH, Jin L and Zhang C: Coculture of stem cells from apical papilla and human umbilical vein endothelial cell under hypoxia increases the formation of three-dimensional vessel-like structures in vitro. Tissue Eng Part A 21: 1163-1172, 2015.

18. Dissanayaka WL, Zhan X, Zhang C, Hargreaves KM, Jin L and Tong EH: Coculture of dental pulp stem cells with endothelial cells enhances osteo-/odontogenic and angiogenic potential in vitro. J Endod 38: 454-463, 2012

19. Lawson ND, Vogel AM and Weinstein BM: sonic hedgehog and vascular endothelial growth factor act upstream of the Notch pathway during arterial endothelial differentiation. Dev Cell 3: $127-136,2002$.

20. Bassaneze V, Barauna VG, Lavini-Ramos C, Kalil J, Schettert IT, Miyakawa AA and Krieger JE: Shear stress induces nitric oxide-mediated vascular endothelial growth factor production in human adipose tissue mesenchymal stem cells. Stem Cells Dev 19: 371-378, 2010.

21. Su W-T, Shih Y-A and Ko C-S: Effect of chitosan conduit under a dynamic culture on the proliferation and neural differentiation of human exfoliated deciduous teeth stem cells. J Tissue Eng Regen Med 10: 507-517, 2016.

22. Su WT, Liao YF, Lin CY and Li LT: Micropillar substrate influences the cellular attachment and laminin expression. J Biomed Mater Res A 93: 1463-1469, 2010.

23. Su WT: Ex vivo expansion of a hematopoietic stem cell on a murine stromal cell by 3D micro-pillar device. Biomed Microdevices 13: 11-17, 2011.

24. Xu JG, Zhu SY, Heng BC, Dissanayaka WL and Zhang CF: TGF- $\beta 1$-induced differentiation of SHED into functional smooth muscle cells. Stem Cell Res Ther 8: 10, 2017.

25. Gong T, Heng BC, Xu J, Zhu S, Yuan C, Lo EC and Zhang C: Decellularized extracellular matrix of human umbilical vein endothelial cells promotes endothelial differentiation of stem cells from exfoliated deciduous teeth. J Biomed Mater Res A 105: 1083-1093, 2017.

26. Ning H, Lin G, Lue TF and Lin CS: Mesenchymal stem cell marker Stro-1 is a $75 \mathrm{kd}$ endothelial antigen. Biochem Biophys Res Commun 413: 353-357, 2011

27. Alison MR, Poulsom R, Otto WR, Vig P, Brittan M, Direkze NC, Preston SL and Wright NA: Plastic adult stem cells: Will they graduate from the school of hard knocks? J Cell Sci 116: 599-603, 2003.

28. dela Paz NG, Walshe TE, Leach LL, Saint-Geniez M and D'Amore PA: Role of shear-stress-induced VEGF expression in endothelial cell survival. J Cell Sci 125: 831-843, 2012.

29. Noguera-Troise I, Daly C, Papadopoulos NJ, Coetzee S, Boland P, Gale NW, Lin HC, Yancopoulos GD and Thurston G: Blockade of Dll4 inhibits tumour growth by promoting non-productive angiogenesis. Novartis Found Symp 283: 106-125, 2007.

30. Liang D, Chang JR, Chin AJ, Smith A, Kelly C, Weinberg ES and Ge R: The role of vascular endothelial growth factor (VEGF) in vasculogenesis, angiogenesis, and hematopoiesis in zebrafish development. Mech Dev 108: 29-43, 2001.

31. Barleon B, Sozzani S, Zhou D, Weich HA, Mantovani A and Marmé D: Migration of human monocytes in response to vascular endothelial growth factor (VEGF) is mediated via the VEGF receptor flt-1. Blood 87: 3336-3343, 1996.

32. Holmes K, Roberts OL, Thomas AM and Cross MJ: Vascular endothelial growth factor receptor-2: Structure, function, intracellular signalling and therapeutic inhibition. Cell Signal 19: 2003-2012, 2007.

33. Yang C, Guo Y, Jadlowiec CC, Li X, Lv W, Model LS, Collins MJ, Kondo Y, Muto A, Shu C, et al: Vascular endothelial growth factor-A inhibits EphB4 and stimulates delta-like ligand 4 expression in adult endothelial cells. J Surg Res 183: 478-486, 2013.

34. Carmeliet P and Jain RK: Molecular mechanisms and clinical applications of angiogenesis. Nature 473: 298-307, 2011. 
35. Bai J, Wang YJ, Liu L and Zhao YL: Ephrin B2 and EphB4 selectively mark arterial and venous vessels in cerebral arteriovenous malformation. J Int Med Res 42: 405-415, 2014.

36. Swift MR and Weinstein BM: Arterial-venous specification during development. Circ Res 104: 576-588, 2009.

37. Pasquale EB: Eph-ephrin bidirectional signaling in physiology and disease. Cell 133: 38-52, 2008.

38. Yang D, Jin C, Ma H, Huang M, Shi GP, Wang J and Xiang M: Ephrin B2/EphB4 pathway in postnatal angiogenesis: A potential therapeutic target for ischemic cardiovascular disease. Angiogenesis 19: 297-309, 2016.

39. Hayashi S, Asahara T, Masuda H, Isner JM and Losordo DW: Functional ephrin-B2 expression for promotive interaction between arterial and venous vessels in postnatal neovascularization. Circulation 111: 2210-2218, 2005.

40. Hainaud P, Contrerès JO, Villemain A, Liu LX, Plouët J, Tobelem G and Dupuy E: The role of the vascular endothelial growth factor-Delta-like 4 ligand/Notch4-ephrin B2 cascade in tumor vessel remodeling and endothelial cell functions. Cancer Res 66: 8501-8510, 2006 .
41. Salvucci O and Tosato G: Essential roles of EphB receptors and EphrinB ligands in endothelial cell function and angiogenesis. Adv Cancer Res 114: 21-57, 2012.

42. Pitulescu ME and Adams RH: Eph/ephrin molecules - a hub for signaling and endocytosis. Genes Dev 24: 2480-2492, 2010.

43. Xue C, Chen Y, Huang Z, Ge Y, Wang H and Wang J: EphB4 expression in pterygium is associated with microvessel density. Int J Clin Exp Med 7: 4008-4015, 2014

44. Kim I, Ryu YS, Kwak HJ, Ahn SY, Oh JL, Yancopoulos GD, Gale NW and Koh GY: EphB ligand, ephrinB2, suppresses the VEGF- and angiopoietin 1-induced Ras/mitogen-activated protein kinase pathway in venous endothelial cells. FASEB J 16: 1126-1128, 2002

(i) (2) This work is licensed under a Creative Commons Attribution-NonCommercial-NoDerivatives 4.0 International (CC BY-NC-ND 4.0) License. 